\title{
JUSTIÇA E VARIÁVEIS LEGAIS \\ PROCESSOS CONTRA ADOLESCENTES VAREJISTAS DO TRÁFICO DE DROGAS ${ }^{1}$
}

\author{
JUSTICE AND LEGAL VARIABLES \\ LAWSUITS AGAINST TEEN DRUG TRAFFICKING RETAILERS
}

\author{
Luzania Barreto Rodrigues \\ Colegiado de Ciências Sociais - Campus Juazeiro, Universidade Federal do Vale do São Francisco, Av. Antônio \\ C. Magalhães, 510 - Country Club, 48902-300 Juazeiro - BA, Brasil. Email: luzania.rodrigues@univasf.edu.br
}

\author{
Paulo Cesar Pontes Fraga \\ Departamento de Ciências Sociais, Instituto de Ciências Humanas, Universidade Federal de Juiz de Fora, Campus \\ Universitário - Rua José Lourenço Kelmer, s/n - São Pedro, 36036-900 Juiz de Fora - MG, Brasil. \\ Email: paulo.fraga@ufjf.edu.br
}

\begin{abstract}
Resumo: O objetivo do artigo é analisar os processos judiciais relativos ao ato infracional de tráfico de drogas, em Petrolina-PE (2011-2014), segundo a Theory of Sentencing. Apreciou-se o conteúdo social das variáveis legais e extralegais, analisando o efeito cumulativo dos determinantes das sentenças. As decisões judiciais mais encontradas foram extinção processual e absolvição. Medidas socioeducativas de advertência, liberdade e semiliberdade são mais recorrentes que a internação. No entanto, há disparidades das sentenças em casos análogos e imputação de penas análogas em casos díspares. Conclui-se que o sistema penal é produtor e reprodutor de desigualdades sociais e a punição é percebida e utilizada como técnica de controle e transformação de adolescentes pobres apreendidos com pequenas quantidades de drogas.
\end{abstract}

Palavras-chave: drogas, adolescentes, justiça e Brasil (Thesaurus das ciências sociais da Unesco).

\begin{abstract}
This article analyzes criminal justice processes of drug trafficking by the Juvenile Court in Petrolina-PE/Brazil (2011-2014) mobilizing the Theory of Sentencing. The social content of the legal and extralegal variables was characterized through the analyzes of the the cumulative effect of the determinants of the sentences. The most frequent judicial decisions were procedural extinction and acquittal. The most applied penalties were warning and probation. Restriction of freedom was less frequent. However, there were disparities of sentences in similar cases and the attribution of analogous sentences in disparate cases. It is concluded that the penal system is a producer and reproducer of social inequalities. In addition, punishment is perceived and used as a technique of control and transformation of poor adolescents seized with small amounts of drugs.
\end{abstract}

Keywords: narcotic drugs, teenagers, justice and Brazil (Unesco Social Science Thesaurus).

\section{Introdução}

O Brasil passou por importantes mudanças de seu ordenamento jurídico nas últimas décadas no intuito de adequar-se às exigências de uma sociedade democrática e com proteção social. A promulgação de uma nova constituinte em 1988 representou o ponto mais alto dessas transformações, exigindo a Carta Magna, não 
obstante, legislações complementares no sentido de adequar políticas, aparato institucional e responsabilidades para a ampla garantia da cidadania.

O Estatuto da Criança e do Adolescente (ECA) foi uma das leis criadas nesse período visando, especificamente, a proteção integral do público a que se destinava. Promulgada em 1990, ela possibilitou avanços na universalização da educação básica, na diminuição da mortalidade infantil, na implementação de programas de saúde voltados às crianças e às grávidas, no reconhecimento de crianças e adolescentes como sujeitos de direitos, e na efetivação de instrumentos legais importantes na maioria dos municípios brasileiros, como os Conselhos de Direitos responsáveis por garantir, formular e acompanhar a implementação das políticas públicas de atendimento à infância e à adolescência - , os Conselhos Tutelares órgão não-jurisdicional, permanente e autônomo, designado pela sociedade a fiscalizar o cumprimento dos direitos da criança e do adolescente - e as Varas da Infância e Juventude, de âmbito municipal ou regional, a qual compete julgar os atos infracionais de crianças e adolescentes em todo o território nacional.

Entretanto, em alguns setores, os indicadores exprimiram dificuldades na garantia da proteção integral. O incremento da maior organização do tráfico de drogas e o envolvimento de adolescentes com essa prática criminal em muitas cidades brasileiras leva ao conseqüente aumento da internação de adolescentes e de homicídios de pessoas nessa faixa etária. No ano de 2014, havia 24.628 adolescentes, entre os 12 e 17 anos de idade, cumprindo medida socioeducativa no Brasil, número seis vezes maior que em 1996 . A maioria por roubo $(44,4 \%)$, secundado pelo ato infracional análogo ao tráfico de drogas, $24 \%$ do total. O Estado de Pernambuco registrou o segundo maior número das preensões, 1.892, precedido apenas por São Paulo, com 10.2112. As Varas da Infância e da Juventude ainda possuem dificuldades em se adequarem ao exponencial aumento da demanda e ao novo ordenamento jurídico (Rodrigues, Ribeiro \& Fraga, 2017), mesmo passados 28 anos após a sua criação (Alvarez, Fraga \& Campos, 2017).

Nesse sentido, o presente artigo visa analisar os processos jurídicos impetrados contra adolescentes da Vara da Infância e da Juventude de Petrolina, Estado de Pernambuco, no período de 2011 a 2014, em virtude dos seus atos infracionais análogos ao crime de tráfico de drogas, previsto na Lei 11.343/06 em consonância com o Estatuto da Criança e do Adolescente. Não há estatísticas municipais acerca do número de adolescentes cumprindo medida socioeducativa. Escolhemos esta Vara por estar localizada na mais importante cidade do Submédio São Francisco, região que detém a maior produção de cannabis do Brasil, também conhecida como Polígono da Maconha. O objetivo é verificar a relação que se estabelece na prática discursiva entre as circunstâncias do ato infracional, a lei e a decisão do juiz. 
O ECA considera ato infracional o comportamento delineado como crime ou contravenção penal. Confirmado o ato infracional, o juiz de direito poderá aplicar sete medidas socioeducativas, levando-se em conta a capacidade do adolescente de cumpri-las, as circunstâncias e a gravidade da infração. São seis as medidas previstas: advertência; obrigação de reparar o dano; prestação de serviços à comunidade; liberdade assistida; inserção em regime de semiliberdade; e, a mais rígida, a internação em estabelecimento educacional.

\section{Material e métodos}

A metodologia utilizada na pesquisa original buscou identificar processos referentes ao tráfico de drogas existentes naquela Vara da Infância e da Juventude. Dentre os 112 processos arquivados, relativos a distintos atos infracionais - como roubo, furto, estupro e assassinato - foram encontrados 24 processos judiciais concernentes ao tráfico de drogas, entre os anos de 2011 e 2014. Este recorte temporal foi escolhido em virtude da disponibilização de processos judiciais sentenciados, raros em períodos anteriores. Para facilitar a análise, haja vista que os processos não poderiam ser retirados da Vara, foram realizadas cópias digitais da íntegra dos processos, com a utilização de um scanner. Após esta etapa, buscamos classificar e categorizar algumas variáveis visando estabelecer perfis. Usamos as categorias sexo, idade, filiação, cor, escolaridade, profissão, exercício de trabalho lícito, profissão dos pais e bairro de moradia. Visando a classificação, empregamos as seguintes categorias jurídicas: associação para o tráfico; reincidência; antecedente; tipo de pena aplicada; duração da pena; testemunha de acusação; testemunha de defesa; elementos que levaram à identificação do tráfico; direito de apelar em liberdade; tipo de substância psicoativa ilegal; quantidade da substância psicoativa ilegal; réu considerava-se usuário; e porte de arma, além de uma categoria extrajurídica: bairro em que o adolescente foi apreendido.

Por meio de uma análise descritiva exploramos este banco de dados documental procurando identificar as variáveis implicadas no fenômeno do envolvimento de adolescentes com o ato infracional equivalente ao crime de tráfico de drogas. O exame dos dados foi realizado com base na Theory of Sentencing, ou Sentencing Traditional para análise de processos judiciais, aplicada em pesquisas de cunho sociocriminológicos, focalizando as possíveis disparidades das penas e nas disposições incorporadas a práxis profissional e social do magistrado (Martins, 2014). A Sentencing Traditional também coteja a desmitificação da neutralidade do juiz de direito nas suas tomadas de decisão, uma vez que considera que seu julgamento é balizado por seu lugar social (Silva, 2015). 
A Theory of Sentencing é um importante instrumento de análise em estudos que buscam investigar sentenças, permitindo uma compreensão ampla das premissas que orientam a prática judicativa (Martins, 2014) e levanta questões acerca da possível contribuição do sistema penal na reprodução de preconceitos e de desigualdade socioeconômicas (Fraga, Silva \& Martins, 2017). Segundo Martins (2014), há uma cultura penal tácita pelos magistrados no início da carreira apreendido por um processo significativo de socialização profissional. Nesse sentido, as disparidades observadas nas penas aplicadas são culturalmente controladas por essa cultura penal, ainda que seja reconhecida a autonomia do poder decisório dos magistrados. Nesse trabalho foram analisadas as sentenças proferidas pelos juízes e realizada uma análise de conteúdo das mesmas levando em consideração variáveis penais utilizadas pelos magistrados.

Assim, uma análise fundada somente em estatísticas oficiais apresenta dificuldades em revelar os meandros de decisões judiciais, tendo em vista que estas são produto da ação dos agentes do controle social formal e do modo como estes operam as leis, a moral, os valores e as crenças. Nesse sentido, a análise qualitativa pode ser ilustrada com elementos estatísticos e objetivos, mas devidamente contextualizados e interpretados pelo pesquisador. Ou seja, não se trata de duas abordagens metodológicas que se excluem, mas de duas perspectivas que se complementam.

\section{A questão da infância e da adolescência e o conceito de menor como categoria política}

Infância, adolescência e juventude constituíam categorias precariamente distintas da idade adulta até o século XVIII, na Europa e nas suas colônias. Somente no século XIX a infância vai ser tratada como categoria efetivamente distinta; a adolescência, no século XX (Ariès, 1981). No Brasil tais noções ganharam clivagens jurídicas, morais e de classe, fazendo emergir a categoria "menor", a qual foi atribuída identidade negativa (Rizzini, 1993). No primeiro instrumento jurídico voltado às crianças e adolescentes, O Código de Menores de 1927, o Juizado de Menores, instituição jurídica a cuidar de casos de crianças e adolescentes em situação irregular ou em conflito com a lei, teria criado um novo padrão de prática jurídica a ser dirigida ao "menor", que passou a ser estudado, examinado e qualificado segundo características morais, físicas, sociais e afetivas. Por isso, antes de ser atendido, aqueles classificados como menores passavam por exames pedagógicos, médico-pedagógicos, médico-psicológicos ou psiquiátricos, "de discernimento" e de "qualificação". Isto foi possível porque uma relação aproximada entre Direito e Psiquiatria 
permitiu a esta última firmar-se enquanto especialidade médica autônoma, fazendo emergir uma modalidade de saber e de poder que tratou de garantir e justificar, sobretudo por funcionar como um mecanismo de higiene pública, voltando-se para gerir populações. O Direito incorporou os frágeis conceitos da psiquiatria como periculosidade, indivíduo perigoso e monomania homicida - em virtude de saber porque punir, isto é, conhecer a natureza do criminoso para tornar justa a punição (Foucault, 2006).

A categoria menor foi ao mesmo tempo um elemento de discriminação entre uma infância pobre e uma infância mais abastada e que representou a forte presença do Estado na institucionalização de crianças e adolescentes. Tal categoria forjou uma estratégia institucional que produziu um sujeito social tratado como sem direitos, indicando que a prática jurídica do Juizado de Menores, por exemplo, não se atinha à concepção estritamente jurídica, uma vez que era dirigida ao denominado menor, caracterizado não apenas pela idade inferior a 18 ou 21 anos, de acordo com a legislação vigente, mas como ator social pertencente à nomeada família desorganizada - categoria cuja definição não elaborava um conceito robusto, mas prenhe de atributos negativos, como a vadiagem, a frouxidão moral e a prostituição. Seu ambiente familiar seria, portanto, contaminado pelos maus costumes, a falta de decoro, a imoralidade, o uso de linguagem de baixo calão, assim como sua aparência seria descuidada, suja e enferma. Tratar-se-ia, ademais, de indivíduos de pouca instrução, que andam em companhias suspeitas e trabalham nas ruas para sobreviver (Rizzini, 1993, p. 96). Como observam Adorno, Bordini e Lima (1999), a descoberta da adolescência como problema é contemporânea da associação entre juventude e delinqüência.

As noções de família desorganizada ou desestruturada, pouco elaboradas e estigmatizantes, ainda hoje têm lugar no imaginário jurídico-penal. Trata-se de um conceito que atrela o ato criminal à biografia dos sujeitos (Foucault, 2006), dando lugar a suposições sobre a vida infracional de crianças e adolescentes, autorizando violências cotidianas como abordagens policiais, revistas, violações de domicílios, confissões forçadas, internação provisória, disciplina prisional e controle pós-disciplinar, como veremos adiante.

Nas primeiras décadas do século XX, a categoria menor abandonado emergiu sob influência das teorias sociobiológicas de Nina Rodrigues. Nesse período, os criminologistas da nova escola penal elegem categorias sociais que devem ser objeto de tratamento jurídico diferenciado, a saber: os loucos, as mulheres e os menores. Combater a infância abandonada converteu-se no projeto civilizador da nação brasileira (Alvarez, 1989). Abundaram, então, as detenções correcionais dos nomeados menores, vadios e toda sorte de excluídos, reforçando o controle das classes 
populares. O Instituto Disciplinar, criado em 1901, institucionaliza a reclusão de menores, segregando-os para, supostamente, regenerá-los. Em 1924, apenas um número diminuto era remetido ao Instituto Disciplinar, sobretudo quando comparado ao alto percentual de detidos sem processo judicial, acusados de contravenções e pequenos delitos patrimoniais e cumprindo o ciclo de detenção e liberação, característico das prisões correcionais (Fausto, 2000). A partir da década de 1930, a reclusão dos "menores" intensifica-se.

No tocante aos estudos acerca das rubricas infância e adolescência, além do mencionado (1) padrão de prática jurídica dirigida ao "menor" e da sua (2) adjetivação negativa e suas consequências sobre os destinos destes jovens atores sociais, devemos atentar para (3) as distintas políticas repressivas e tutelares a eles dirigidas desde 1970.

O Código de Menores foi o primeiro conjunto de leis elaborado no Brasil para as crianças, elaborado exclusivamente para o controle da infância e da adolescência abandonadas e delinquentes (Marcílio, 1998, p. 224). Estas eram medidas de controle, distintas daquelas medidas de intervenção, proteção e assistência implementadas nos anos de 1960, particularmente em 1964, ano do golpe militar. Estabelece-se aí o Estado Interventor, autodenominado Estado de Bem-Estar Social e é criada a FUNABEM - Fundação Nacional do Bem-Estar do Menor. Até 1978 a FUNABEM era regulamentada pelo seu Estatuto. A partir de 1979 entra em vigor o novo Código de Menores, o qual vem regular a fundação das FEBEM - Fundação Estadual para o Bem-Estar do Menor, destinadas a operar a recepção, triagem e observação das crianças e adolescentes, bem como a garantir sua permanência na Instituição.

De acordo com Marques (1976), esse código foi construído com base na premissa de que o menor é vítima de uma sociedade de consumo, desumana e cruel, e, como tal, deveria ser tratado e não punido, ter acesso à preparação profissional, em vez de ser estigmatizado como infrator. No seu entender, a sociedade furtou-se de oferecer assistência e educação ao menor, por isto este personagem não pode ser tratado com rigor penal, mas com medidas inspiradas na pedagogia corretiva (Marques, 1976, p. 114).

No entanto, o Código de Menores de 1979 manteve a base do Código de 1927. O novo Código prevê a sua incidência sobre "o menor que revele conduta anti-social", aquela que inclua ato considerado legalmente crime ou contravenção. Desse modo, o Código de Menores de 1979 exclui as categorias menor exposto, menor transviado, menor infrator, menor delinquente, menor transgressor e menor abandonado, e as substitui pelas categorias menor carente e menor de conduta antissocial, por entender seus relatores que estas últimas não seriam 
ofensivas ou estigmatizas em relação as primeiras (Marques, 1976, p. 117). No entanto, o denominado menor carente e o menor de conduta antissocial continuavam sendo apreendidos nas ruas das cidades brasileiras pelo policiamento ostensivo das rondas dos Comissariados de Menores, passando por triagens e investigações realizados pelos Juizados, por Delegacias de Menores e pelos Centros de Triagens das FEBEM, e, em seguida, retirados da sua vida em grupo (familial ou de rua) e confinados nas instituições ditas de proteção, sob o signo da ressocialização (Silva, 1990, p. 46).

Nos anos de 1970, o "menor abandonado" - problema social a ser erradicado nas malhas das instituições correcionais - se transformará em menor de rua, dada sua eloquente presença na cidade. As mudanças retóricas legais não impediram que práticas legais ou extralegais de abuso e de afronta aos direitos humanos contra crianças e adolescentes continuassem. Nos anos de 1980, crianças e adolescentes alvo de extermínio eram, via de regra, traficantes varejistas de drogas ilícitas ou aqueles que cometiam pequenos furtos e roubos, que se mantinham livres mediante subornos a policiais militares e sucumbiam quando os valores cobrados por estes eram aviltantes. A exacerbação da violência policial incidia, sobremaneira, contra tais traficantes e os trombadinhas, que sintetizavam no imaginário social a delinquência urbana (Teixeira, 2012, p. 189).

Na década de 1980, a repercussão da violência perpetrada contra crianças e adolescentes fez os movimentos sociais pelos direitos humanos reagirem, propondo uma agenda de debate público acerca das distintas formas de violência sofridas por essa jovem parcela da população, deslocando o foco da delinquência da qual eram acusados. A mobilização desses movimentos foram exponenciadas com a promulgação do Estatuto da Criança e do Adolescente (ECA), que veio reconhecer crianças e adolescentes enquanto sujeitos de direitos que devem gozar proteção integral.

O ECA, por sua vez, veio descentralizar o poder Estatal, exercido até então, sobre as crianças e adolescentes, distribuindo-o e repartindo-o com os Estados e Municípios. Isto é, a antiga política nacional do bem-estar do menor, aprovada em dezembro de 1964, Lei 4.513, foi substituída pela Constituição de 1988 e pelo ECA, de 1990, os quais delegaram poderes aos municípios para definir a política peculiar local para a infância e a adolescência (Paula, 2017). É, pois, sob a égide do ECA que são julgados crianças e adolescentes em conflito com a lei nas Varas da Infância e da Juventude, em processos judiciais que nos propusemos a analisar aqui.

O que se objetiva destacar nessa discussão é o surgimento das categorias menor e criança no aparato institucional não como meros substantivos, mas, antes, 
servindo para adjetivar a infância, criando uma separação semântica e de práticas entre uma suposta infância boa e uma infância ruim e condenando esta última a um destino preocupante. Apesar de mudanças substantivas na concepção de atenção e nos direitos de crianças e de adolescentes, tal separação e classificação ainda hoje flui no interior das práticas e dos discursos jurídicos e militares, conforme observamos no fluxo dos processos judiciais examinados, na Vara Regional da Infância e da Juventude da Comarca de Petrolina.

No presente artigo, o intuito é analisar o fluxo dos processos judiciais relacionados ao comércio varejista de drogas ilícitas nesta Vara. Ao cotejar as informações contidas nos Inquéritos, foi possível aceder à descrição da apreensão do adolescente por meio da ronda policial - ou da denúncia anônima de tráfico varejista - e ao perfil dos acusados de tal ato infracional. Também apreciamos o conteúdo social das variáveis consideradas legais - como os níveis de responsabilização dos adolescentes nos argumentos jurídicos, proferidos por promotores, advogados de defesa e pelo juiz de direito, bem como aqueles extralegais, como as classificações morais e discriminatórias arranjadas nos discursos destes mesmos profissionais, a fim de analisar o efeito cumulativo dos determinantes das sentenças.

\section{Resultados}

Nos 24 processos analisados, foram julgados 27 adolescentes, sendo que em três dos processos foram ajuizados dois adolescentes. Em relação ao sexo, 3 jovens eram do sexo feminino e 24 jovens do sexo masculino. As idades dessas pessoas variavam entre os 14 e 17 anos de idade. Informações acerca do nível educacional apontaram 1 jovem analfabeto, outros 19 com ensino fundamental incompleto, 5 com ensino médio incompleto e em três processos não constava a escolaridade do adolescente.

No Brasil, vários indicadores sociais nas áreas de saúde, educação e segurança pública utilizam a informação sobre a cor de pele. Tal procedimento não visa discriminar negativamente, mas, ao contrário, serve como informação para subsidiar ações de políticas públicas compensatórias visando a melhoria dos índices. Nos processos analisados em quinze deles não constava a cor da pele dos processados, oito foram identificados como negros e cinco como pardos. Nenhum adolescente foi identificado como branco.

Treze dentre eles exerciam trabalhos lícitos no momento da apreensão policial, todos em postos não profissionalizados, em funções mal remuneradas, sendo que a maioria não era na condição de aprendiz de uma profissão reconhecida pelo Ministério do Trabalho, como determina o ECA (Tabela 1). 
Tabela 1 Ocupações laborais no momento da prisão

\begin{tabular}{lc}
\hline Ocupação laboral & Frequência \\
\hline Não trabalhava & 14 \\
Ajudante de pedreiro & 2 \\
Trabalhador rural & 3 \\
Auxiliar de eletricista & 1 \\
Lavador de carro & 2 \\
Carroceiro & 1 \\
Catadora de lixo para reciclagem & 1 \\
Empregada doméstica & 3 \\
Total & 27 \\
\hline
\end{tabular}

Tabela 2 Antecedentes criminais por crimes cometidos

\begin{tabular}{lc}
\hline Crimes praticados anteriormente & Frequência \\
\hline Não possui antecedentes & 18 \\
Homicídio & 2 \\
Furto & 2 \\
Tráfico de drogas & 3 \\
Roubo & 1 \\
Porte de armas & 1 \\
Total & 27 \\
\hline
\end{tabular}

Na maioria dos processos não constava a profissão dos pais, aquelas identificadas foram as de ajudante de pedreiro, trabalhador(a) rural e diarista. A maioria não era reincidente ou tinha qualquer passagem pelo sistema policial ou judiciário, isto é, do total dos adolescentes, apenas oito deles já se encontravam em conflito com a lei, respondendo processos por homicídio, furto, tráfico, roubo e porte de arma (Tabela 2).

Nos processos, policiais militares constavam como as únicas testemunhas de acusação, aqueles que fazem a descrição da conduta dos acusados na fase inquisitorial, deixando refletir critérios, valores e ideologias das suas corporações, as quais constituem "subculturas do sistema penal" (Hulsman, 2009, p. 24). É com base em tais formulários, os Boletins de Ocorrência, que o juiz tipifica a infração e infere a prova de autoria, como apontado alhures (Silva, 2015, p. 54). Não há testemunha de defesa nos processos avaliados, excetuando-se duas ocasiões: no primeiro, consta apenas o nome da testemunha, sem dados sobre seu perfil; noutro, no qual um adolescente transportava maconha de uma cidade da região para outra, seu conterrâneo, agricultor, atesta a boa índole do rapaz acusado. 
As conformações familiais encontradas foram as seguintes: 2 pais falecidos, 5 pais desconhecidos, adolescente criado pela mãe sem ajuda do pai, embora o pai fosse reconhecido em seu registro de nascimento, e em 20 casos o pai consta no registro. Em nenhum caso a figura paterna acompanhou o filho à delegacia ou ao juízo, a cumprir o papel de responsável legal. Este papel é assumido pela figura materna, excetuando-se dois casos em que foram constituídos responsáveis legais uma irmã e um irmão.

A maioria deles foram apreendidos no centro da cidade ou em bairros da periferia da cidade. Segundo os relatos dos boletins de ocorrências, contidos no processo, a prisão possui características comuns: a apreensão dá-se durante a ronda policial ou através de denúncia anônima. O roteiro se repete: policiais avistam os adolescentes em "atitudes suspeitas" - as quais nunca são definidas ou descritas -, revistam-nos, encontram pequena quantidade de psicoativos ilícitos e conduzem-nos às suas residências. Lá, segundo depoimento dos policiais, sempre com autorização dos adolescentes ou dos seus familiares, revistam a casa e encontram maior quantidade da substância apreendida com os adolescentes. Em todos os processos, nenhum pai ou mãe negou autorização aos policiais e em nenhuma residência deixou-se de encontrar drogas proscritas.

Se o tráfico de drogas constitui crime permanente, o que legitimaria a busca nas residências dos adolescentes sem mandado judicial, não é apenas nestes casos que tal busca se dá (Fraga \& Silva, 2016). Isto é, apesar de estarmos analisando exclusivamente processos judiciais relativos ao ato infracional análogo ao tráfico de drogas, encontramos um processo em que o adolescente foi abordado pela Polícia Militar quando dirigia uma motocicleta e se encontrava sem Carteira Nacional de Habilitação. Ato contínuo, em vez de simplesmente autuá-lo, os agentes policiais, sem qualquer argumento mencionado no processo, levaram-no até a sua residência e revistaram-na, com o objetivo de procurar drogas, encontrando 25 gramas de crack no interior da residência. Tratava-se de um adolescente que exercia a função de auxiliar de eletricista, afrodescendente, contando 17 anos de idade e com ensino médio incompleto. O juiz de direito decretou sua internação provisória - que durou 26 dias - e, ao final, aplicou-lhe a sanção de "advertência" e "liberdade assistida", com acompanhamento de 6 meses da sua vida social, familiar e escolar, com remessa de pedido de relatório semestral sobre seu comportamento para a direção da sua escola e do Centro de Internação Provisória - CENIP.

Enfim, embora esse adolescente tenha declarado que ainda iria começar a vender a substância tornada ilícita, passou quase sete meses em atividades definidas pelo Estado. Uma combinação de "disciplina prisional" com "controle pós-disciplinar", medidas para evitar a reincidência, fator primordial para a boa 
avaliação dos sistemas socioeducativos (Malvasi, 2012). Em outro caso, o inquérito policial foi aberto, segundo informações no processo judicial, porque a polícia foi até a residência do adolescente ao receber informações anônimas de que ele agrediu a irmã com cabo de vassoura. Sem nenhum indício de tráfico de drogas - que permitisse a realização de busca e apreensão nos domicílios sem mandato judicial -, os agentes policiais realizaram busca e apreensão na casa, e teriam encontrado 65 pedras de crack e 231 reais que pertenceriam ao adolescente de 17 anos de idade, ajudante de pedreiro, com ensino fundamental incompleto, morador de bairro da periferia da cidade, cuja mãe era trabalhadora rural.

Dentre os 24 processos judiciais em apreço, sete deles foram extintos. Dentre as sete extinções processuais, quatro delas se deram em virtude de o adolescente já se encontrar cumprindo medidas socioeducativas em razão de outros atos infracionais, o que leva o juiz a propugnar por unificação das medidas. Outros três processos foram extintos porque os adolescentes não foram encontrados para responder ao processo. Destes, dois foram encontrados dois anos depois, quando já haviam alcançado a maioridade penal: um cumprindo pena por tráfico de drogas e, outra, liberada por ter-se tornado cuidadora da mãe esquizofrênica e da sua filha de três anos de idade, além de estar grávida e trabalhando como catadora de material reciclável, tendo sido considerada "em ressocialização". Tratam-se, nos dois casos, de processos que duraram dois anos, demandando vãos esforços do sistema penal.

O oitavo caso de extinção processual é deveras inusitado. O adolescente teria agredido fisicamente sua irmã e guardava consigo 65 gramas de crack. Inicialmente, o promotor defendeu sua internação provisória, asseverando que "o adolescente praticou atos infracionais extremamente graves e está submetido a intenso risco, ante a possibilidade de inserção em grupo de risco (traficantes e usuários de drogas)". O juiz acolhe o pedido da promotoria, argumentando que houve gravidade na conduta do evento, determinando sua internação provisória e, posteriormente, sentenciando-o à medida de Internação por três anos, a ser reavaliada a cada três meses. Na primeira reavaliação, baseando-se no relatório técnico da Fundação de Atendimento Socioeducativo (FUNASE), o promotor posicionou-se contra o pedido da defesa, que requereu a liberação do adolescente. Argumentou que "o menor" se envolveu em rebelião no interior da unidade de internação, "realizando atos de vandalismo, a exemplo de queima de colchões". O juiz entendeu que o adolescente deveria permanecer internado, "a fim de que se possa aquilatar sua progressão e seu bom desenvolvimento, requisitos indispensáveis para a sua reinserção na sociedade", afirmando ser as instituições de internação efetivamente cumpridoras de tal função social. Na segunda reavaliação, o advogado da FUNASE, seu defensor, baseado no parecer psicossocial da instituição, pede a 
progressão da medida socioeducativa, clamando pela medida de Prestação de Serviço à Comunidade, uma vez que o adolescente teria manifestado bom comportamento durante todo o lapso temporal da sua internação e, portanto, deveria "retornar ao convívio social". O juiz, então, sentencia a extinção do processo judicial.

Estes oito processos foram abertos em razão do tráfico varejista de diminuta escala. Num dos casos, o adolescente fora acusado de vender crack a um adulto e teria confessado aos policiais, contudo não portava uma grama sequer. Nos demais, adolescentes portariam consigo desde 3 a 33 gramas de crack, ou 3,93g a 21g de maconha. Houve um único caso em que a quantidade de psicoativo ilícito saiu da escala de centigramas e gramas para contar-se por quilo, no qual o adolescente possuía $4,7 \mathrm{~kg}$ de maconha. Dentre os processos analisados além destes oito supra que foram extintos, 8 adolescentes foram absolvidos, 8 receberam medida de advertência, liberdade assistida e semiliberdade; e 2 foram condenados à medida de internação e em um deles a página final da sentença não constava a sentença.

Os adolescentes absolvidos foram apreendidos portando de zero a 42 pedras de crack, com exceção de um que detinha 3 gramas de cocaína e 50 reais e outro que portava 65 gramas de maconha. $\mathrm{O}$ adolescente acusado de vender crack, e que não possuía qualquer quantidade da droga, foi absolvido da acusação de ato infracional análogo ao crime de tráfico por falta de provas materiais. A polícia abriu inquérito que redundou em processo judicial baseando-se em "materialidade indireta". Tratou-se de um adolescente de 15 anos de idade, que exercia trabalho lícito como ajudante de pedreiro. Dois adolescentes que traziam consigo três pedras de crack foram absolvidos em virtude da fragilidade das provas e negação de autoria delitiva, em processos judiciais distintos. Num deles, a Promotora de Justiça entende "que o ato infracional praticado pelo adolescente é de repercussão reduzida, não ocasionando graves consequências, de modo que não se faz necessário o desenvolvimento do processo judicial", solicitando remissão e advertência. O juiz acatou, entendendo que o ato seria de pequena gravidade. Caso análogo foi de um adolescente acusado de tráfico por estar em companhia de adultos que portavam 42 pedras de crack, no qual o promotor de justiça argumentou que teria ficado provado que o adolescente não cometeu o ato infracional, em virtude da negação da autoria e do testemunho de um dos policiais afirmando que a droga não se encontrava com o acusado.

As medidas de advertência proferidas pelo juiz de direito podem ou não estar combinadas com medidas socioeducativas - como semiliberdade e liberdade assistida - ou com medidas complementares, a exemplo do acompanhamento da vida social, familiar e escolar. Dentre os adolescentes a que foram imputadas medidas 
de advertência combinadas a outras medidas, dois foram destinados a cumprir liberdade assistida, um semiliberdade e dois de acompanhamento escolar.

Em três processos distintos os adolescentes foram absolvidos sob a argumentação da defesa de os adolescentes acusados não estarem envolvidos em outros atos infracionais, encontrando-se em processo de ressocialização e demonstravam arrependimento. Nesses casos, os 3 adolescentes acusados fizeram, respectivamente, tráfico varejista de 65 gramas de maconha e 5 e 25 pedras de crack. As medidas de advertência foram somadas ao acompanhamento escolar, familiar e social por parte do Centro de Internação Provisória - CENIP. Nos dois casos em que aos adolescentes foram impetradas medidas exclusivamente de Advertência, os adolescentes haviam atingido a maioridade penal ao final do processo judicial, razão pela qual, de acordo com o juiz de direito, não teriam "capacidade" de cumprir medida socioeducativa. Num dos casos, o adolescente detinha 117 pedras de crack, ou 13,6 gramas. Em outros casos dois adolescentes, trabalhadores rurais, mantinham consigo 11,34 gramas de crack. O primeiro processo durou dois anos; o segundo, um ano e meio. A incapacidade de cumprimento da medida socioeducativa de advertência atribuída pelos operadores do direito aos adolescentes estava perfeitamente em conformidade com a lei, apontando para uma exitosa imagem do judiciário como disciplinador. Frente a casos como estes, é flagrante a urgência de reflexão jurídica e social acerca do tratamento a ser dispensado àqueles que alcançam a idade limite e ficam sem a proteção do ECA.

Nos dois casos em que foram combinadas medida de advertência e medida de liberdade assistida durante seis meses, um adolescente transportava 221 gramas de cocaína; o outro, 2 pedras de crack, 12 petecas de cocaína, 1 trouxa de maconha, $\mathrm{R} \$ 166,00$ reais e um celular NOKIA C-100. Nas sentenças, o juiz argumenta que os adolescentes cometeram ato infracional sem violência ou grave ameaça, não havendo maiores danos para a sociedade. No primeiro caso, quando da sua apresentação ao Ministério Público, consta que "o adolescente tem vasta folha de antecedentes de atos infracionais" e responde a outros dois processos judiciais, pelo que o juiz de direito determina a unificação dos autos e das medidas socioeducativas. Durante o andamento do processo, foi-lhe concedido apelar em liberdade sob fiscalização do Centro de Referência Especializado de Assistência Social - CREAS. No segundo caso, a defesa argumentou que o adolescente não era reincidente nem possuía maus antecedentes infracionais e que a medida de internação possui princípios próprios a serem seguidos, como a excepcionalidade, de acordo com a qual a internação só é aplicável quando se mostram inadequadas todas as outras medidas socioeducativas, propugnando pela liberdade assistida e asseverando que a experiência de internação poderia suprimir no adolescente "sua ingenuidade", que 
seria "tomada de assalto". O juiz entende que a medida em meio aberto de liberdade assistida seria uma "forma de incentivar os seus estudos e fortalecer seus laços familiares".

Estes dois casos tiveram a mesma sentença, o que pode indicar que a reincidência ou os considerados maus antecedentes infracionais não foram decisivos para a determinação da medida socioeducativa a ser imposta, como o juiz e o promotor desta Vara Regional da Infância e Juventude da Comarca de Petrolina argumentaram nos demais processos aqui em análise. Observa-se que a quantidade de substância psicoativa ilícita igualmente não tenha influenciado a decisão judicial acima, uma vez que, em um dos casos que o juiz proferiu a sentença de medida socioeducativa de internação com duração de três anos, o adolescente portava 6 gramas de crack, o que o magistrado considerou "uma quantidade significativa da droga".

Ojulgamento parece ser balizado pela subjetividade do magistrado, circunstancialmente manifesta. O fato de o adolescente não trabalhar ou estudar, além de ser reincidente, é determinante para aquilatar a pena, uma vez que considera agravantes tais quesitos. A mesma medida socioeducativa foi sancionada para um adolescente que possuía 4,7 quilos de maconha, era reincidente e tinha maus antecedentes infracionais - roubo e posse ilegal de armas. Via de regra, a reincidência é determinante, ou os antecedentes infracionais, impondo-se à violação da garantia de proibição "de dupla punição pelo mesmo fato" (Karam, 2008, p. 111). Viola-se, também, o princípio da isonomia, o qual determina que pessoas em igual situação devem ser igualmente tratadas (Karam, 2008, p. 110). Tais procedimentos parecem apontar para importância que o magistrado atribui à punição ao adolescente, levando em conta sua biografia, seu suposto grau de periculosidade e sua conformação familial.

Um adolescente que transportava 3,9 quilos de cannabis de um município do Agreste Pernambucano a outro, prestando serviço de "mula", foi preso em flagrante delito e internado provisoriamente em face "da robusta materialidade da autoria e da gravidade do ato infracional e sua repercussão social" e, também nas palavras da juíza de direito, em virtude do "risco em potencial de que esse adolescente se enverede pelo caminho obscuro da criminalidade". No bojo do processo judicial, a juíza de direito do caso argumenta que

... a conduta do adolescente demonstra a necessidade do afastamento temporário do menor do convívio social e familiar a que está habituado, para que reveja e reeduque sua conduta, possibilitando a reintegração social e as garantias de seus direitos individuais e sociais. Evidencia-se, portanto, a necessidade imperiosa de internação provisória. (Processo judicial da Vara da Infância de Petrolina) 
Este adolescente foi encaminhado ao CENIP/FUNASE de Petrolina-PE a fim de ser incluído "em atividades pedagógicas compatíveis com suas aptidões", devendo a instituição apresentar relatório ao Juízo. Doravante, o parecer técnico da equipe multidisciplinar na FUNASE, contido no bojo do processo judicial, atesta que

o adolescente tem bom comportamento, interage com os outros internos e com os funcionários do estabelecimento, tendo demonstrado profundo arrependimento pelo que fez. A conduta desviada do adolescente, embora grave por ser extremamente perniciosa à saúde pública, não merece aplicação de medida socioeducativa de internação, haja vista que o menor não possui antecedentes infracionais, do que se conclui que medida menos severa será capaz de ressocializá-lo e contribuir para a reestruturação do seu caráter, sobretudo diante da demonstração de arrependimento do jovem. (Processo judicial da Vara da Infância de Petrolina)

O advogado de defesa propugnou por medida de Semiliberdade. O promotor concordou com a defesa. A juíza de direito o submeteu à medida de Semiliberdade por tempo indeterminado, com avaliação a cada seis meses. Aqui, parece ficar patente que "o adolescente em conflito com a lei" é ao mesmo tempo visto como perigoso e vulnerável, e que a demonstração de arrependimento constitui a senha para escapar da internação, o que este jovem personagem dá ares de perceber e acionar.

\section{Discussão}

A análise dos processos leva à conclusão que a apreensão de adolescentes envolvidos ou acusados por tráfico de drogas parece transcorrer de acordo com a lei. A polícia, após capturar os adolescentes, conduzem-nos às delegacias e, ato contínuo, à Vara da Infância e da Juventude. No entanto, a seletividade da ação policial é o diferencial dessas apreensões, pois concentra a repressão apenas nos bairros da periferia e possui um modelo padrão que se repete (Alvarez, Fraga \& Campos, 2017). O caráter classista da repressão policial padroniza aqueles que serão apreendidos. Os processos e as medidas socioeducativas aplicadas parecem, também, indicar seletividade da justiça e do sistema policial (Boiteux, 2015), dedicados a perseguir, julgar e condenar adolescentes com o mesmo perfil socioeconômico. Nas periferias urbanas de pequenas, médias e grandes cidades brasileiras, os agentes policiais continuam prendendo o "menor infrator". Mudaram as leis, mas as condutas policiais pouco mudaram e, em alguns casos, tornaram-se mais repressivas.

Por outro lado, os operadores do direito parecem ainda não terem incorporado ou possuem dificuldades em atualizar suas práticas profissionais com o 
estabelecido no ECA, instrumento de proteção integral. Sua condição é ontológica. É a terminologia que estigmatiza, encontrada nos inquéritos policiais e nos testemunhos de acusação em juízo dos soldados que os apreendem. A terminologia "menor", que cria tanto estigma, está incrustada no seu linguajar, deveras incorporada que está na conduta profissional de tais agentes. Por suas mãos, os adolescentes em conflito com a lei continuam sendo menores infratores. As condutas policiais padronizadas, que leva os adolescentes aos seus lares, onde sempre é encontrada a droga, parece ser consequência de arbitrariedades policiais, pois não fica claro em que condições elas acontecem, pois as ações sempre terminam no mesmo local.

De acordo com o art. 5, inciso 11, da Constituição Federal, buscas em residências devem ser realizadas mediante autorização da Justiça. Entretanto, a Lei 11.343/06, em seu artigo 33, define que manter entorpecentes em depósito constitui delito permanente. De acordo com o Supremo Tribunal Federal, "o artigo 330 do Código de Processo Penal considera como situação de flagrância aquele que estiver cometendo crime permanentemente". Foi com base nestes argumentos que a Suprema Corte brasileira definiu que a polícia pode apreender drogas nas residências sem mandato judicial (Galli, 2015). As buscas policiais são feitas, via de regra, em casa de pessoas pobres, periféricas e com baixa instrução, com históricos de violação de direitos e sem condições de reagir a qualquer arbítrio policial. É o que demonstra eloquentemente os dados aqui em análise, corroborados por aqueles encontrados na Vara da Infância e da Juventude em Juazeiro, Estado da Bahia (Rodrigues, Ribeiro \& Fraga, 2017). Ademais, esta decisão da Suprema Corte data de 2015 , ano posterior àqueles relativos aos processos judiciais que compõem nosso banco de dados (2011-2014). Isto é, antes mesmo da decisão da Suprema Corte as buscas e apreensões policiais sem mandato judicial nas residências desses adolescentes eram corriqueiras.

O magistrado, por sua vez, limita-se a indicar os termos da medida - como a inserção na escola, no trabalho e na família, a eliminar seu estigma de perigoso e infrator que lhe foi imprimido no próprio processo judicial -, com vistas a uma adequação a um padrão socialmente aceito, sem atentar às condições objetivas para alcançá-la, o que já foi verificado em outros estudos em varas da infância e juventude (Sartório \& Rosa, 2010).

Ao examinarmos os processos judiciais, verificamos que assistentes sociais, psicólogos, advogados, oficiais de justiça e juízes de direito não escapam a essa prática discursiva. O movimento pendular persistente entre adolescência e o termo menoridade a contaminar o corpo institucional, mormente seu linguajar. O uso do termo menor é tão recorrente que chega a ser usado mesmo para designar 
documento jurídico, como o Termo de Audiência de Ouvida Prévia de Menor. A categoria menor, portanto, é uma importante designação política, pois define ações, distingue sujeito e imprime punições (Foucault, 2006). Enfim, a adjetivação da adolescência pobre é uma constante, concorrendo para transformar sua prática circunstancial em destino indelével (Alvarez, Fraga \& Campos, 2017).

A reincidência é o elemento primordial na condenação do adolescente. Esta é, sem dúvida, a categoria que mais pune. O destino inevitável do adolescente apreendido é selado, na prática, quando um ato é julgado duas vezes, isto é, quando um ato infracional passado pode influenciar sobremaneira a decisão judicial, na forma de reincidência ou antecedentes criminais. Sem dúvida, os procedimentos judiciais distam das práticas policiais no que concerne aos óbvios juízos de valor impregnados nestas últimas. Suas decisões são balizadas, mais propensas à extinção processual - embora, amiúde, em razão da unificação das medidas socioeducativas - e à absolvição; as medidas socioeducativas de advertência, liberdade e semiliberdade são mais recorrentes que a medidas mais duras, como a de internação. No entanto, não são neutras ou universais, vide as disparidades das sentenças em casos análogos e a imputação de penas análogas em casos díspares (Martins, 2014).

De modo geral, o sistema penal brasileiro reforça as desigualdades sociais (Hulsman, 2009; Hulsman \& Celis, 1993), despende de esforços profissionais que poderiam estar direcionados à resolução de crimes ou atos infracionais violentos. A maioria dos processos decorridos entre 2011 e 2014, na Vara, em Petrolina, foram abertos contra adolescentes que portavam quantidades muito pequenas de psicoativos ilícitos. Outros estudos mostram que essa prática não é isolada nos tribunais brasileiros (Boiteux, 2015; Campos \& Alvarez, 2017). Tais adolescentes não têm seus direitos assegurados no rito do direito porque o sistema penal coaduna com o rudimentar discurso público acerca da guerra às drogas, na falsa polarização entre crime e sociedade, bandido e trabalhador, legal e ilegal (Malvasi, 2012, p. 244). As violações de direitos são recorrentes, forças policiais e judiciárias costumam abrir inquéritos e processos judiciais improcedentes (Campos \& Alvarez, 2017). Um das questões mais complexas na análise das sentenças é verificar como juízes naturalizam práticas ilegais. A moral concentra-se na legitimação do trabalho, mesmo desenvolvido de forma irregular. O trabalho infantil e juvenil ilegal é aceito e defendido por juízes de direito e promotores de justiça, quando argumentam nas sentenças seu caráter pedagógico, uma vez que manteria crianças e adolescentes longe das ruas, locus de mendicância, promiscuidade e de ações delituosas (Lourenço, 2014, p. 298). O trabalho precoce, ilegal segundo a legislação brasileira, paradoxalmente é legitimado por autoridades judiciárias, 
deixando de ser percebido em sua negatividade, mas, ao contrário, visto como instrumento de prevenção da marginalidade e da delinquência: "O ideal passa a ser o aprendizado de uma profissão, mesmo que esta seja precária, insegura e que represente riscos à saúde da pessoa em desenvolvimento" (Lourenço, 2014, p. 302) e ao seu próprio desenvolvimento intelectual e profissional. Na perspectiva dessa racionalidade, compreende-se que as situações ilegais e irregulares vivenciadas por adolescentes pobres figuram como profiláticas na prevenção da criminalidade. Nesse sentido, parece que se fecha o ciclo da reprodução da pobreza: trabalhando e frequentando uma escola precária, crianças e adolescentes tornar-se-ão adultos que terão necessidade de contar com o trabalho infanto-juvenil da sua prole.

Os argumentos de acusação, decisivos para a sentença a ser postulada pelo juiz de direito, baseiam-se em quesitos como a quantidade da droga encontrada e em outros itens que o adolescente mantenha em posse quando apreendido - geralmente, dinheiro trocado; na gravidade do fato - se cometido ou não mediante grave ameaça ou violência; na capacidade de o adolescente cumprir a medida proposta; a demonstração de arrependimento por parte do adolescente, sua busca e inserção no processo de ressocialização, aí incluído bom comportamento durante a internação provisória, retomada dos estudos formais e a inserção em trabalho lícito.

O que se pode notar é uma tensão entre proteção, controle, direito, moral e segurança pública, transparecendo mais a preocupação com a defesa da sociedade, o que é legítimo, mas excluindo dessa mesma sociedade o adolescente pobre. Além disso, resta evidenciado que o adolescente tem que primeiro passar pela experiência infracional, ser inserido no sistema socioeducativo e, por último, ter acesso aos programas sociais, numa clara inversão das medidas de proteção social, em flagrante inobservância aos seus direitos sociais previstos em lei, como já apontaram Silva (2005) e Schuch (2005). Note-se que a defesa da sociedade, mediante o controle da juventude pobre, à sua revelia e em seu prejuízo, está no bojo das Propostas de Emenda à Constituição, apresentadas no Parlamento desde 1993, relativas à redução da maioridade penal no Brasil, de 18 para 16, 14 ou 12 anos de idade (Campos, 2009).

\section{Conclusão}

Discutiu-se nesse artigo as mudanças legais dos procedimentos de apreensão de crianças e adolescentes no Brasil em conflito com a lei. A questão do adolescente infrator sempre foi tratada, ao longo do período republicano no Brasil, de forma 
institucionalizada, buscando preservar a sociedade de possíveis danos que a ela poderia ser causado em detrimento da ressocialização desses atores. A promulgação do ECA, importante instrumento baseado na defesa dos direitos humanos e de convenções internacionais de proteção à criança e ao adolescente, dos quais o Brasil é signatário, não mudou significativamente esse histórico, notadamente porque o judiciário e as polícias continuaram com práticas e ações institucionais que ignoram os preceitos fundamentais desse instrumento legal.

No caso específico de Petrolina, verificamos procedimentos da polícia e do judiciário que reforçam a idéia da punição, sem a contrapartida estatal da proteção. Mesmo quando se remete no discurso à proteção do adolescente com medidas de internação, ignora-se a incapacidade do sistema de reabilitar, por carência de equipamentos públicos para esse fim. Assim, a dimensão discursiva guarda correspondência com a prática policial e judicial, orientada pela vaga e eternizada ideia de "atitude suspeita" de crianças e adolescentes radicados em territórios periféricos, o que resulta no controle disciplinar da infância e adolescência pobres pelo sistema de justiça criminal durante os longos períodos de cumprimento da medida de advertência, que chegam a durar dois anos.

Reincidência, antecedentes infracionais, quantidade de drogas apreendida, inserção em escola formal e em trabalho, formal ou informal, são comumente considerados para a apuração da medida educativa, sendo os três primeiros quesitos considerados agravantes e os dois últimos, atenuantes. Mas há exceções e disparidades, o que aponta para a influência da subjetividade do magistrado na tomada de decisão, para a constante duplicação da punição pelo mesmo fato e para a inobservância do princípio da isonomia. Disso resulta a perpetuação da divisão entre menoridade e infância e adolescência inserida e protegida, com acentuada influência de uma política de drogas esboçada e mantida para punir os pobres (Wacquant, 2008) e isentar o Estado de elaborar e implementar políticas públicas promotoras de bem-estar. Assim, a categoria menor, utilizada ao longo da história brasileira, é uma categoria política. Ela é o antagonismo das categorias criança e adolescente e serve para diferenciar os que devem ser protegidos dos que devem ser punidos.

\section{Notas}

1. Esse artigo de investigação científica está baseado na pesquisa de pós-doutoramento Adolescentes e jovens no plantio ilícito de cannabis e no tráfico de drogas em três cidades da região do Vale do São Francisco: Influência das motivações individuais e de elementos estruturais desenvolvida no programa de pós-graduação em ciências sociais da 
Universidade Federal de Juiz de Fora, realizado entre março de 2017 e fevereiro de 2018. No Brasil, a expressão "tráfico varejista" tem sido cunhada para referir-se ao comércio de pequenas ou diminutas quantidades de droga - medidas em gramas ou centigramas -, distinto do denominado narcotráfico.

2. De acordo com o $11^{\circ}$ Anuário Brasileiro de Segurança Pública. Disponível em http:/ / www.forumseguranca.org.br/wp-content/uploads / 2019/01/ ANUARIO_11_2017.pdf. Acesso em: 21/01/2019.

Por decisão pessoal, a autora e o co-autor do texto escrevem segundo o novo acordo ortográfico.

\section{Referências}

Adorno, S., Bordini, E. B. T., \& Lima, R. S. de (1999). O adolescente e as mudanças na criminalidade urbana. São Paulo em Perspectiva, 13(4), 62-74. DOI: 10.1590/S0102-88391999000400007

Alvarez, M. C. (1989). A emergência do Código de Menores de 1927: Uma análise do discurso jurídico e institucional da assistência e proteção aos menores (Tese de mestrado não publicada). USP, São Paulo.

Alvarez, M., Fraga, P., \& Campos, M. (2017). Perspectivas atuais sobre políticas, produção, comércio e uso de drogas: Apresentação ao dossiê "Drogas e sociedade em uma perspectiva comparada". Tempo Social, 29(2), 1-14. DOI:

10.11606/0103-2070.ts.2017.133303

Ariès, P. (1981). História social da criança e da família. Rio de Janeiro: LTC.

Boiteux, L. (2015). El antimodelobrasileño: Prohibicionismo, encarcelamiento y selectividad penal frente al tráfico de drogas. Nueva Sociedad, 255, 132-144.

Campos, M. (2009). Mídia e política: A construção da agenda nas propostas de redução da maioridade penal na Câmara dos Deputados. Opinião Publica, 15(2). DOI: 10.1590/S0104-62762009000200008

Campos, M., \& Alvarez, M. (2017). Pela metade: Implicações do dispositivo médico-criminal da "Nova" Lei de Drogas na cidade de São Paulo. Tempo Social, 29(2), 45-73. DOI: 10.11606/0103-2070.ts.2017.127567

Fausto, B. (2000). Crime e cotidiano: A criminalidade em São Paulo (1880-1924). São Paulo: EDUSP.

Foucault, M. (2006). Ditos e escritos: Ética, sexualidade e política. Rio de Janeiro: Forense Universitária.

Fraga, P. C. P., \& Silva, J. N. (2016). As ações de contenção aos plantios ilícitos no Brasil: Repressão policial e políticas governamentais. Revista Debates Latinoamericanos, 14(1), 72.

Fraga, P. C. P., Silva, J. N., \& Martins, R. S. (2017). Mujeres y criminalidad: Um estudio sobre la participación de lãs mujeresen el cultivo de cannabis en el Vale do São Francisco, Brasil. Estudios Sociológicos, 35(1), 547-570. DOI:

10.24201/es.2017v35n105.1498 
Hulsman, L. A. (2009). Perspectiva abolicionista: Apresentação em dois tempos - Qual abolição?. Verve. Revista Semestral Autogestionária do Nu-Sol, 15(1), 18-32.

Hulsman, L., \& Celis, P. (1993). Penas perdidas: O sistema penal em questão. Niterói: Luam Editora LTDA.

Galli, M. (2015). Flagrante delito: Polícia pode apreender drogas dentro de casa sem mandato, decide Supremo. São Paulo: CONJUR.

Karam, M. L. (2008). A Lei 11.343/06 e os repetidos danos do proibicionismo. In B. Labate (Ed.), Drogas e cultura: Novas perspectivas (pp. 105-120). Salvador: EDUFBA.

Lourenço, E. A. de S. (2014). Reestruturação produtiva, trabalho informal e invisibilidade social de crianças e adolescentes. Serv. Social e Sociedade, 118(1), 294-317. DOI: 10.1590/S0101-66282014000200005

Malvasi, P. A. (2012). Interfaces da vida loka: Um estudo sobre jovens, tráfico de drogas e violência em São Paulo (Tese de doutorado não publicada). USP, São Paulo.

Marcílio, M. L. (1998). História social da criança abandonada. São Paulo: Hucitec.

Marques, J. B. (1976). Marginalização: Menor e criminalidade. São Paulo: McGraw-Hill do Brasil.

Martins, R. S. (2014). Estupro de criança e adolescentes e a desigualdade nos tribunais: Uma análise dos processos judiciais. Lisboa: NEA.

Paula, L. de (2017). Punição e cidadania: Adolescentes e liberdade assistida na cidade de São Paulo. São Paulo: Alameda Casa Editorial.

Rizzini, I. (Ed.) (1993). O elogio do científico: A construção do "menor" na prática jurídica. In A criança no Brasil hoje: Desafio para o terceiro milênio (pp. 28-62). Rio de Janeiro: EDUSU.

Rodrigues, L. B., Ribeiro, M. da S., \& Fraga, P. C. P. (2017). O envolvimento de adolescentes no tráfico de drogas em Juazeiro - Norte da Bahia: Uma análise do fluxo dos processos judiciais da Vara da Infância e da Juventude. Teoria e Cultura, 12(1), 241-252.

Sartório, A. T., \& Rosa, E. M. (2010). Novos paradigmas e velhos discursos: Analisando processos de adolescentes em conflito com a lei. Serv. Soc. Soc., 103(1), 554-575. DOI: $10.1590 / 0102.3772 \mathrm{e} 3337$

Schuch, P. (2005). Práticas de justiça: Uma etnografia do campo de atenção ao adolescente infrator no Rio Grande do Sul, depois do Estatuto da Criança e do Adolescente (Tese de doutoramento não publicada). UFRGS, Porto Alegre.

Silva, A. F. do A. (1990). A mutação judicial. In A. C. Costa, et al. (Eds.), Brasil criança urgente. A Lei 8069/90: O que é preciso saber sobre os novos direitos da criança e do adolescente (pp. 114-127). São Paulo: Columbus Cultural.

Silva, M. O. (2005). O controle sócio-penal dos adolescentes com processos judiciais em São Paulo: Entre a "proteção" e a "punição" (Tese de doutoramento não publicada). PUC-SP, São Paulo.

Silva, J. N. (2015). Mulheres no tráfico de drogas: Um estudo sobre os determinantes da condenação na cidade de Juiz de Fora, Minas Gerais. In P. C. P. Fraga (Ed.), Mulheres e criminalidade (pp. 47-80). Rio de Janeiro: Letra Capital. 
Teixeira, A. (2012). Construir a delinquência, articular a criminalidade: Um estudo sobre a gestão dos ilegalismos na cidade de São Paulo (Tese de doutorado não publicada). USP, São Paulo.

Wacquant, L. (2008) Punishing the poor: The neoliberal government of social insecurity. Durham e Londres: Duke University Press.

Data de submissão: 27/10/2018 | Data de aceitação: 26/11/2018 